\title{
Determinants Of Non-Performing Loans: An Empirical Investigation Of Bank- Specific Microeconomic Factors
}

\author{
Amir Ikram, Xi' an Jiaotong University, China \\ Qin Su, Xi'an Jiaotong University, China \\ Faisal Ijaz, University of Gujrat, Pakistan \\ Muhammad Fiaz, Xi'an Jiaotong University, China
}

\begin{abstract}
The empirical study was undertaken to explore the determinants of non-performing loans (NPLs) of small and medium enterprises (SMEs) sector held by the commercial banks. Stratified sampling technique was used to collect primary data through well-structured survey questionnaire from credit analysts / bankers of 42 branches of 9 commercial banks, operating in the district of Lahore (Pakistan), for 2014-2015. Selective descriptive analysis and Pearson chi-square technique were used to illustrate and evaluate the significance of different variables affecting NPLs. Branch age, duration of the loan, and credit policy were found to be significant determinants of NPLs. The study proposes that bank-specific and SME-specific microeconomic variables directly influence NPLs, while macroeconomic factors act as intermediary variables. The results elaborate various origins of NPLs and suggest that they are primarily instigated by the loan sanctioning procedure of the financial institution. The paper also underlines the risk management practices adopted by the bank at branch level to averse the risk of loan default. Empirical investigation of bank-specific microeconomic factors of NPLs with respect to Pakistan's economy is the novelty of the study. Broader strategic policy implications are provided for credit analysts and entrepreneurs.
\end{abstract}

Keywords: Non-Performing Loans; Small And Medium Enterprises; Commercial Banks, Microeconomic Factors; Pakistan

\section{INTRODUCTION}

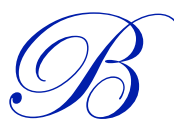

anking sector plays a vital role in the economic development of a country. Though bank facilities and loans are mutually beneficial, but banks do suffer the risk of loss that some loans may become nonperforming and this discourages them to grant loans to small and medium enterprises (SMEs). The global financial crisis of 2007-2008 was precisely attributed to non-performing loans (NPLs) of banks and mortgage firms; the increased debt burden and over-leveraging was too severe that the fourth-largest investment bank of USA, Lehman Brothers Holdings Inc., got bankrupt in 2008 (Swedberg, 2010). For developing countries, the role of banks becomes even more imperative as SMEs rely heavily on loans to pursue their growth and sustainability objectives (Ikram \& Su, 2015; Rasool, Dars \& Shah, 2013). In fact, NPLs is such a grave issue that the very survival of banks depends on it (Saba et al., 2012). It is perhaps the most important indicator of financial stability since it depicts credit risk, operational risk and resources allocation efficiency. Thus it is of paramount importance to figure out the determinants of NPLs and suggest pragmatic implications to minimize the risk. Though the definition of NPLs varies from country to country, there is some convergence of opinion among scholars and institutions. As per IMF's Compilation Guide on Financial Soundness Indicators 2004 (Guide): “A loan is nonperforming when payments of interest and/or principal are past due by 90 days or more, or interest payments equal to 90 days or more have been capitalized, refinanced, or delayed by agreement, or payments are less than 90 days overdue, but there are other good reasons to doubt that payments will be made in full". State Bank of Pakistan states: "NPLs are loans and advances whose markup/interest or principal is overdue by 90 days or more from the due date". 
The notion of NPLs has substantial importance not only for bank management but also for policy makers and academicians. Many scholars investigated the relationship between macroeconomic factors and non-performing loans, but little work has been done to explore the relationship between bank specific microeconomic factors and non-performing loans. In this study we examine the Pakistani financial industry by restricting our focus to the commercial banks. We endeavor to fill the literature gap by examining the influence of bank-specific and microlevel variables of NPLs for banking sector within the city of Lahore, Pakistan. We also examine the implications of micro-level factors with respect to causal nexus of NPLs, and evaluate risk management practices for its effective control. The rest of the study proceeds as follows. The next section discusses empirical related literature on NPLs and its implications for Pakistan, determinants and solutions thereof. In the next section, we elaborate the research methodology and formulate hypotheses to gauge the relationship between NPLs and its determinants. Section 4 presents the findings of empirical analysis. Conclusions and recommendations for future study are discussed in the last section.

\section{LITERATURE REVIEW}

\subsection{NPLs and its Implications for the Economy of Pakistan}

NPLs are a byproduct of performing loans and needs to be treated as an undesirable output (Guarda, Rouabah, and Vardanyan, 2012). Barseghyan (2010) suggests that NPLs has widespread social and economic implications, as they reduce social output and diminishes the production growth. Pakistan is facing various socio-economic problems and performance of various key sectors, such as steel industry, is depicting diminishing growth over the last decade or so (Ikram et al., 2016). World development indicators (World Bank, 2013) suggest that Pakistan accounts for the highest NPL ratio among Asian countries. Thus the issue of NPLs has rigorous implications for developing countries like Pakistan, where SMEs constitute a major chunk of the economy (Rasool et al., 2013). Haneef et al. (2012) propose that Pakistan's banking sector is short of proper mechanism for risk management, which leads to NPLs. Energy crisis is regarded as one of the significant determinant of productivity for SMEs and has immensely hampered their growth (Ikram, Su \& Asif, 2016), Farhan et al. (2012) conducted an empirical study on commercial banks of Pakistan and advocates that electricity crisis is one of the reasons for loan default on the part of SMEs. He further suggests that that interest rate, energy crisis, unemployment, inflation, and exchange rate has a significant positive relationship with the non-performing loans, while GDP growth exhibits significant negative relationship with the NPLs. Since Pakistan heavily relies on IMF to cover its fiscal deficit, interest rate is being influenced by IMF bound regulations (Ramiz et al., 2016).

The loan default has always been an issue of grave concern for both lenders and policy makers (Saba et al., 2012). The opportunity cost for provisioning of NPLs is quite extreme, Zhu et al. (2014) deployed shadow price to measure the opportunity cost and concluded that they immensely lessen efficiency of the banking sector. In fact, NPLs mark the beginning of banking or financial crisis (Kumar \& Woo, 2015). Another aspect of non-performing loan is that bulk of it is related to SMEs (Greenidge \& Grosvenor, 2010). Ekanayake and Azeez (2015) intend that the level of NPLs can be ascribed to both macroeconomic environment and banks' specific aspects. They further suggest that larger banks incur lesser loan defaults as compared to smaller banks, and NPLs has negative relationship with the GDP growth rate of GDP and inflation. Beck, Jakubik and Piloiu (2013) conducted econometric analysis of the novel panel data from 75 countries and shows that real GDP growth, lending mark-up rate and exchange rate significantly affect NPLs. Macroeconomic factors such as GDP growth, unemployment, and inflation are significant explanatory variables of NPLs (Greenidge and Grosvenor, 2010; Klein, 2013; Louzis, Vouldis and Metaxas, 2012; Makri et al., 2014; Saba et al., 2012), and bank-level factors, for example size, quality of the bank's management, and lending policy, are also important determinants of NPLs (Greenidge and Grosvenor, 2010; Klein, 2013; Louzis et al., 2012). Shimizu (2011) witnessed that relationship gaps between SMEs and small lending institutions results in bank default. Moreover, loan classification is found to be associated with NPLs; business loans rate changes with GDP growth rate, consumer loans changes with lending rates, except mortgages which do not change regardless of change in macro-economic indicators (Louzis et al., 2012). Another interesting macroeconomic aspect of NPLs, Ramiz et al. (2016) coupled NPLs with political system of a country by conducting an empirical investigation of the banking sector, and suggests that NPLs of overall banking industry of Pakistan are strongly related to its political environment, and proposes that political interference and stability are significant macroeconomic determinants of 
NPLs. For the purpose of this study, our focus will be on bank and SME specific microeconomic variables.

\subsection{Tackling the Issue of NPLs}

Kamran et al. (2016) examined 8 western countries of the world based on GDP over a period from 1998 to 2010, and advocated that there exists significant relationship between risk premium and bank's non-performing loans. Durafe and Singh (2016) deployed multiple regression analysis and exhibited that bank specific variables have significant effect on NPLs, while macroeconomic variables were found to be insignificant in presence of bank specific variables. Nonperforming assets reduce banks' willingness and ability to supply credit because provisioning against NPLs hamper profitability and arises operating costs, and this creates problems for SMEs with borderline credit quality (Richard, 2011). Thus comprehensive measures are required to minimize the negative impact of vicious circle of NPLs. Banks and financial institutions need to deploy specialized internal and external capability for managing nonperforming assets, keenly control their provisions, and write off their nonperforming assets (Hart \& Moore, 1997). Non-payment ration can be reduced if the banks utilize credit scoring methods to analyze credit requests, due to the gaps not keenly observed by other lending institutions (Young, Glennon, \& Nigro, 2007). Moreover, bank's insolvency can be tackled by restricting government loan guarantees, and let the market forces to interact and decide the loan repayment ratio. Nonetheless, this idea is not feasible for the governments due to its political counter effects (Choe, 2007).

\section{RESEARCH METHODOLOGY \& HYPOTHESES DEVELOPMENT}

The study is carried out to explore the impact of various microeconomic and bank-specific factors affecting NPLs held by the bank against loan sanctioned to SMEs. As per archives of State Bank of Pakistan, there are 284 branches of different banks operating in the Lahore district by December 2015. To serve the purpose, stratified sampling technique was deployed to collect primary data from 47 branches of 9 commercial banks in a proportionate manner through a well-constructed questionnaire (see Appendix), out of which 5 branches did not respond, which depicts a healthy response rate of $93 \%$. Thus our final sample is 42 branches of 9 commercial banks operating in the city of Lahore, Pakistan, under categories, a) Public Sector Commercial Banks, b) Specialized banks, c) Domestic Private Banks; the major chunk of data has been collected from the last category as this comprises highest number of banks operating in the country. Supplementary data was collected from quarterly reviews of State Bank of Pakistan, Economic Survey of Pakistan, and publications of Federal Bureau of Statistics and World Bank reports. Figure 1 depicts research modus operandi in detail and gives bird's eye view of the study; it also reports the selected commercial banks and their respective categories in the data collection portion.

Sample size $=42$ (Branches of 9 different commercial banks working in Lahore)

\subsection{Research Hypotheses}

Hypotheses were developed to find out the association between the bank-specific microeconomic variables and NPLs. In the next section, we shall test the hypotheses through statistical technique of Pearson's Chi-Square Analysis, and analyze the dynamics of data collected through selective descriptive statistics. We formulate the following hypotheses on the basis of objectives of the study and literature review (section 2):

$\mathbf{H}_{1}$ : Nature of collateral significantly influences the value of non-performing loan.

$\mathbf{H}_{2}$ : There is association between valuation of collateral demanded by the banks and value of non-performing loans.

$\mathbf{H}_{3}$ : There is significant relationship between bank-specific credit policy and NPLs:

$\mathbf{H}_{4}$ : Value of non-performing loans depends on the age of the branch.

$\mathbf{H}_{5}$ : Repayment capacity of firm \& value of non-performing loan are significantly related with each other.

$\mathbf{H}_{6}$ : There is association between term of loan and NPLs value.

Copyright by author(s); $\underline{\text { CC-BY }} 1725$

$\underline{\text { The Clute Institute }}$ 
Figure 2. Research Process

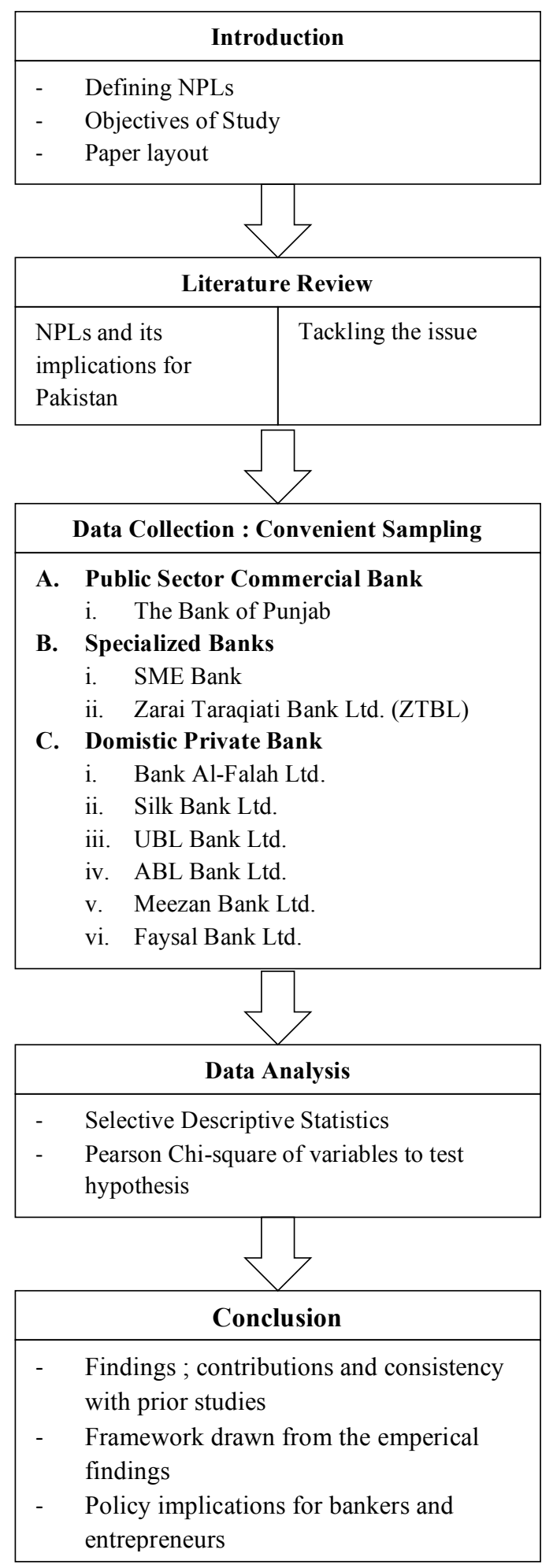




\section{DATA ANALYSIS}

In order to empirically test the hypotheses, SPSS statistical software was used to perform factor analysis of descriptive statistics for selected variables and Pearson's correlation analysis was deployed to test hypotheses that we set forth in Section 3.

\subsection{Descriptive Analysis}

\subsubsection{Age of Branch}

Table 1 depicts that almost $45 \%$ bank branches of the sample data fall in the range of 5 years and above, followed by $26.2 \%$ fall in the category of $3-5$ years of operations.

Table 1. Age of bank branch

\begin{tabular}{|c|c|c|}
\hline Age of Branch & Frequency & Percent \\
\hline $0-2$ year & 6 & 14.3 \\
\hline $2-3$ years & 6 & 14.3 \\
\hline $3-5$ years & 11 & 26.2 \\
\hline $5 \&$ above & 19 & 45.2 \\
\hline
\end{tabular}

\subsubsection{Nature of Collateral desired by the Banks}

Table 2 shows the most preferred type of collateral desired by the banks is residential with $67 \%$, followed by $21 \%$ for commercial and $12 \%$ for agricultural land. The highest percentage for residential ownership is understandable as it usually generates least amount of ownership issues in case of default. Presumably, there is convenience in selling residential property in case of default. In contrast, commercial property is not much desirable on account of ownership issues. And agricultural land is acquired by the banks dealing in agricultural-based lending, e.g. Zarai Traqiati Bank.

Table 2. Nature of collateral

\begin{tabular}{l|c|c}
\hline \multicolumn{1}{c}{ Nature of Collateral } & Frequency & Percent \\
\hline Residential & 28 & 66.7 \\
\hline Commercial & 9 & 21.4 \\
\hline Agricultural land & 5 & 11.9 \\
\hline
\end{tabular}

\subsubsection{Degree of Collateral Up-To Which Loan is Sanctioned}

Loan sanction limit is depicted in Table 3, which shows that approximately $62 \%$ of the banks sanction loan for 70 $\%$ of the collateral. Since the values of collateral or property for that matter is quite fluctuating, banks' risk aversive behavior is understandable.

Table 3. Percentage degree of collateral

\begin{tabular}{|c|c|c|}
\hline Degree of Collateral & Frequency & Percent \\
\hline $60 \%$ & 16 & 38.1 \\
\hline $70 \%$ & 26 & 61.9 \\
\hline
\end{tabular}




\subsubsection{Measure to Reduce the Level of NPLs}

Table 4 shows relative frequencies of different measures adopted by the bank to reduce the level of non-performingloans. The most influencing factor supported by the responses is 'constant dialogue with the borrowers' with $57 \%$, followed by re -structuring of debt with $19 \%$.

Table 4. Various measures to reduce NPLs

\begin{tabular}{l|cc}
\hline \multicolumn{1}{c|}{ Measures to reduce NPL } & Frequency & Percent \\
\hline Constant dialogue with borrowers & 24 & 57.1 \\
\hline Restructuring of debt & 8 & 19.0 \\
\hline Waiver of interest amount \& recovery of principal & 5 & 11.9 \\
\hline Judicial Proceedings & 5 & 11.9 \\
\hline
\end{tabular}

\subsubsection{Macro-Economic Conditions as Suggested by Bankers}

Table 5 portrays bankers' perception with respect to the different macro-economic problems faced by the Pakistani SMEs. The most significant problem rated by the respondents is the high interest rate with $29 \%$, followed by $21 \%$ for high electricity prices, and lack of infrastructure received least attention with just $14 \%$.

Table 5. Macro-economic factors

\begin{tabular}{l|c|c}
\hline \multicolumn{1}{c}{ Macro-Economic problems } & Frequency & Percent \\
\hline High interest rate (i) & 12 & 28.6 \\
\hline Inflation & 7 & 16.7 \\
\hline Lack of infrastructure & 6 & 14.3 \\
\hline High electricity prices & 9 & 21.4 \\
\hline Lack of govt. support & 8 & 19.0 \\
\hline
\end{tabular}

\subsection{Pearson Correlation Analysis to Test Hypotheses}

H1: Nature of collateral significantly influences the value of non-performing loan.

For issuance of loan, the nature of collateral could be either residential, or commercial, or agricultural land. It was observed that bankers usually prefer residential land. As per table 6, Pearson's chi-square value is 4.295 with Pvalue of 0.368 , which implies that there is insignificant association between the two variables at both $\alpha$ values of $0.05 \& 0.10$.

Table 6. Nature of collateral significantly and NPLs

\begin{tabular}{l|c|c|c}
\hline \multicolumn{1}{c|}{ Test } & Value & Df & Asymp. Sig. (2-sided) \\
\hline Pearson Chi-Square & 4.295 & 4 & .368 \\
\hline Likelihood Ratio & 5.587 & 4 & .232 \\
\hline Linear-by-Linear Association & 0.668 & 1 & .414 \\
\hline N of Valid Cases & 42 & & \\
\hline
\end{tabular}

H2: There is significant association between valuation of collateral and value of non-performing loans.

The hypothesis was established to find out the association between valuation method adopted by the banks at the time of issuance of loan and value of NPLs. In Pakistan, collateral is usually assessed by IBP approved evaluator, or independent surveyor or banker could evaluate the market value of the asset on its own. Table 7 exhibits chi-Square value of 5.01 with corresponding P-value of 0.286 , thus the study suggests insignificant association found between the two the variables i.e. valuation of collateral and NPLs at usual levels of significance ( $\alpha$ value $0.05 \& .10$ ). 
Table 7. Valuation of collateral and NPLs

\begin{tabular}{l|c|c|c}
\hline & Value & df & Asymp. Sig. (2-sided) \\
\hline Pearson Chi-Square & 5.01 & 4 & 0.286 \\
\hline Likelihood Ratio & 5.15 & 4 & 0.272 \\
\hline Linear-by-Linear Association & 0.19 & 1 & 0.660 \\
\hline N of Valid Cases & 42 & & \\
\hline
\end{tabular}

H3: There is significant relationship between bank-specific credit policy and NPLs.

Nature of contract and credit policy of the bank is usually related to degree of collateral or selection criteria for borrowers. Our investigation observes significant association between bank-specific credit policy and value of NPLs (see Table 8).

Table 8. Bank-specific credit policy and NPLs

\begin{tabular}{l|c|c|c}
\hline & Value & df & Asymp. Sig. (2-sided) \\
\hline Pearson Chi-Square & 12.325 & 6 & .05 \\
\hline Likelihood Ratio & 13.360 & 6 & .038 \\
\hline Linear-by-Linear Association & .627 & 1 & .428 \\
\hline N of Valid Cases & 42 & & \\
\hline
\end{tabular}

H4: Value of non-performing loans depends on the age of the branch.

Descriptive statistics depict that majority of the bank branches under consideration have age of 5 or more. It is interesting to know whether non-performing loans depends on the age of concerned branch. Table 9 shows P-value (0.031) is less than 5\% level of significance, so there is significant association between the age of branch and value of NPLs.

Table 9. Age of bank branch and NPLs

\begin{tabular}{l|c|c|c}
\hline & Value & df & Asymp. Sig. (2-sided) \\
\hline Pearson Chi-Square & 13.841 & 6 & .031 \\
\hline Likelihood Ratio & 14.377 & 6 & .026 \\
\hline Linear-by-Linear Association & 4.581 & 1 & .032 \\
\hline N of Valid Cases & 42 & & \\
\hline
\end{tabular}

H5: Repayment capacity of firm \& value of non-performing loan are significantly related with each other.

Repayment capacity of SMEs is generally determined through sales output, repayment record or analysis of their financial statements. Table 10 indicates insignificant association between repayment capacity of firm and value of NPLs as P-value of 0.30 is greater than greater than level of significance (i.e. $0.30>\alpha 0.05 \& 0.10$ ). This depicts the prevalence of political interference and willful defaults on the part of borrowers.

Table 10. Repayment capacity and NPLs

\begin{tabular}{l|c|c|c}
\hline & Value & Df & Asymp. Sig. (2-sided) \\
\hline Pearson Chi-Square & 7.230 & 6 & .30 \\
\hline Likelihood Ratio & 8.406 & 6 & .21 \\
\hline Linear-by-Linear Association & .059 & 1 & .81 \\
\hline N of Valid Cases & 42 & & \\
\hline
\end{tabular}


H6: There is association between duration of loan \& NPLs.

For bankers and credit analysts, it is imperative to know whether the term of loan affects the level of NPLs. The association between term of loan and value of NPLs is significant at $10 \%$ level of significance (P-value $=0.07<\alpha=$ 0.10). This is explicable considering the unstable political and economic environment in which bankers and SMEs operate.

Table 11. Duration of loan \& NPLs

\begin{tabular}{l|c|c|c}
\hline & Value & Df & Asymp. Sig. (2-sided) \\
\hline Pearson Chi-Square & 6.416 & 4 & 0.07 \\
\hline Likelihood Ratio & 6.641 & 4 & 0.05 \\
\hline N of Valid Cases & 42 & & \\
\hline
\end{tabular}

\section{DISCUSSION}

Based on the findings of the study and thorough review of relevant literature, our study endorses the view of Durafe and Singh (2016) that microeconomic factors directly influence NPLs. Figure 2 depicts the framework drawn from the empirical findings and exhibits the causal nexus of NPLs.

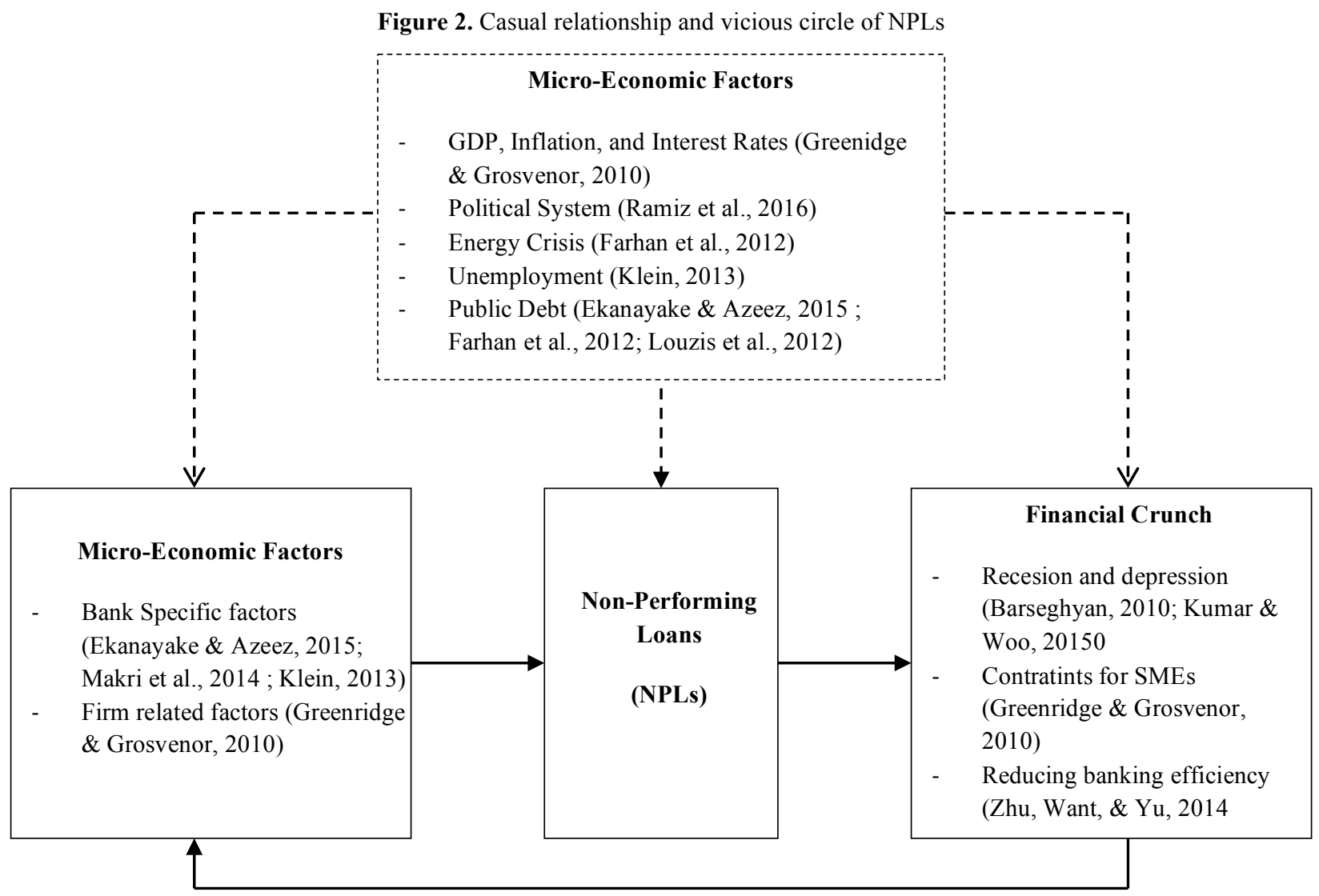


The vicious circle illustrates that sustainable growth cannot be achieved without a sound and resilient banking system. Kumar and Woo (2010) suggest that high debt usually slows down growth and leads to financial instability. Low per capita and high interest rate result in low repaying capacity of borrowers, and can ultimately leads to bad debts. Macroeconomic factors act as intervening factors and affect the whole nexus; and this is consistent with prior studies (Farhan et al., 2012; Greenidge and Grosvenor, 2010; Klein, 2013). Macro-economic reasons for Pakistan might include factors such as corruption, energy crisis, political instability, unemployment, GDP growth rate, inflation and high interest rate (Ikram \& Su, 2015; Ramiz et al., 2016). Though these factors do not have a direct impact on the level of NPLs, but they influence SMEs' performance and reduce their repayment capacity to pay off bank's loan. Whereas, micro factors encompass both bank-specific and firm-specific factors, such as age of bank branch, nature of collateral and willful defaults. Our study explores the causality of NPLs by empirically investigating bank-specific and SME-specific microeconomic variables, and findings of the study have broader strategic implications for financial institutions, entrepreneurs and policy makers.

\section{CONCLUSION AND IMPLICATIONS OF THE STUDY}

The study is carried out to explore the impact of various bank specific factors affecting NPLs held by the banks against loan sanctioned to SMEs. It has widespread implications for loan sanctioning procedure of the financial institutions. The issue of NPLs has always remained an issue of great importance for the banking sector literature. Prior studies examined various external factors of the banks which proved to have enormous effect on the quantum of NPLs. Conversely, this study aimed at exploring the bank specific procedural aspects which ultimately affects the level of NPLs. The authors formulated six hypotheses to test the effects of bank specific and SME related microeconomic factors on NPLs, namely nature of collateral, valuation of collateral, credit policy, age of the branch, repayment capacity of the firm and term of loan. Credit policy (nature of contract), age of the bank branch and term of the loan found to have significant impact on NPLs. While repayment capacity of the SME, nature and valuation of collateral found to exhibit insignificant association with NPLs. Therefore, collateral related factors, such as valuation method and nature of collateral, should be given secondary importance as it was found that they do not have considerable impact on the level of NPLs. First and foremost, bankers should articulate credit policy properly after thorough investigation of the borrower, and efforts should be made to keep the term of loan to the minimum. One interesting dimension of the findings is insignificant impact of repayment capacity of the borrower, which can be attributed to willful defaults on the part of SMEs and prevalence of political intervention or nepotism.

The results elaborate that various origins of NPLs are closely associated with each other. For instance, improper selection of borrower is the foremost cause instigated by the loan sanctioning procedure and fully handled by the bank itself, accompanied by improper appraisal of collateral which can decline the bank's recovery in case of default. Willful default of the borrower is another aspect which is required to be keenly sorted out. The above stated procedural lapses on the part of banks lead to the increase in the quantum of NPLs, specifically for SMEs' sector. Another imperative aspect of NPLs is associated with the time span, i.e. age of particular branch of a bank. The study exhibits that the age factor is closely linked to the level of NPLs. It is consistent with the common understanding that the bank branch is in a better position to filter out SMEs with maturity. SMEs rely heavily on the bank's facility for their continuation and growth objectives. Thus banks need to vigilantly utilize their funds for the development of SMEs and country as a whole. Financial institutions should not sleep over its funds after issuance, rather they should ensure proper disposal of funds by the borrower. Further, they should forecast the future business prospects and market dynamics on continual basis. The scope of the research can be extended by including more external and macro-economic factors, for example the influence of corporate governance on NPLs can be taken into consideration. Additionally, the paper can be extended beyond Lahore district, say at provincial or country level, in order to enhance generalizability.

\section{ACKNOWLEDGEMENTS}

The authors are grateful to State Key Laboratory for Manufacturing Systems Engineering, Key Lab of the Ministry of Education for Process Control and Efficiency Engineering, and School of Management of Xian Jiaotong University, China. The research contribution has also been supported by 'National Natural Science Foundation of China [Project Number: 71371151]' and 'Humanities and Social Sciences of Ministry of Education Planning Fund [13YJA630078]'.

Copyright by author(s); $\underline{\text { CC-BY }}$ 


\section{AUTHOR BIOGRAPHIES}

Amir Ikram is Ph.D. scholar at School of Management, State Key Laboratory for Manufacturing Systems Engineering, Xi'an Jiaotong University, China. His interests lie in entrepreneurship, cluster strategy and regional development. amirikram12@hotmail.com (Corresponding author)

Dr. Qin Su is doctoral tutor and assistant dean at School of Management, Xi'an Jiaotong University. Her research interests include quality management, industrial engineering, and enterprise management. She has authored more than 200 peer-reviewed articles in leading international journals. qinsu@mail.xjtu.edu.cn

Faisal Ijaz is education manager at University of Gujrat, Pakistan. He also serves as visiting faculty member at various private and public sector institutions of Lahore, Pakistan. His research interests are related to finance, banking, entrepreneurship and economic development. formanite06@gmail.com

Dr. Muhammad Fiaz is Post-doctorate fellow at School of Management, Xi'an Jiaotong University. He is also serving as faculty member at IB\&M, UET Lahore and has more than 10 years of teaching experience at university level. His research interests are related to R\&D collaboration, additive manufacturing, entrepreneurship and quality management.

\section{REFERENCES}

Barseghyan, L. (2010). Non-performing loans, prospective bailouts, and Japan's slowdown. Journal of Monetary Economics, 57(7), 873-890.

Beck, R., Jakubik, P., \&Piloiu, A. (2013). Non-performing loans: What matters in addition to the economic cycle?.

Choe, C. (2007). The political economy of SME financing and Japaa's regional Bank Problems. Pacific Basin Finance Journal, 15, 353-367.

Durafe, A., \& Singh, M. (2016). Cyclical Behavior of Public and Private Sector Banks: A Comparative Study of Non-Performing Assets. Journal of Business and Management Research, 1(1), 14-25.

Ekanayake, E. M. N. N., \& Azeez, A. A. (2015). Determinants of Non-Performing Loans in Licensed Commercial Banks: Evidence from Sri Lanka. Asian Economic and Financial Review, 5(6), 868.

Farhan, M., Sattar, A., Chaudhry, A. H., \& Khalil, F. (2012). Economic Determinants of Non-Performing Loans: Perception of Pakistani Bankers. European journal of business and Management, 4(19), 87-99.

Greenidge, K. and Grosvenor, T. (2010). Forecasting non-performing loans in Barbados. Journal of Business, Finance and Economics in Emerging Economies, 5, 80-107

Guarda, P., Rouabah, A., \&Vardanyan, M. (2012). Identifying bank outputs and inputs with a directional technology distance function. Journal of Productivity Analysis, http://dx.doi.org/10.1007/s11123-012-0326-7

Haneef, S., Riaz, T., Ramzan, M., Rana, M. A., Ishaq, H. M., \& Karim, Y. (2012). Impact of risk management on non-performing loans and profitability of banking sector of Pakistan. International Journal of Business and Social Science, 3(7), 308-315.

Ikram, A., Su, Q., \& Rafiq, M. Y. (2016). Time series modelling for steel production. The Journal of Developing Areas, 50(3), 191-207. doi.org/10.1353/jda.2016.0112

Ikram, A., \& Su, Q. (2015). Determinants of Productivity in the Ready-made Garments SMEs of Lahore, Pakistan. In Proceedings of the 5th International Asia Conference on Industrial Engineering and Management Innovation (IEMI2014) (pp. 81-86). Atlantis Press.

Ikram, A., Su, Q., \& Sadiq, M. A. (2016). Technical Efficiency And Its Determinants: An Empirical Study Of Surgical Instruments Cluster Of Pakistan. Journal of Applied Business Research (JABR), 32(2), 647. doi.org/10.19030/jabr.v32i2.9601

Kamran, H. W., Malik, S., Hamas Butt, M. H., Afzal, U., \& Maqbool, S. (2016). Risk Premium and Its Effect on Bank's Non-Performing Loans. Risk,1(6), 0 .

Klein, N. (2013). Non-performing loans in CESEE: Determinants and impact on macroeconomic performance.

Kumar, M., and J. Woo. (2010). "Public Debt and Growth." Working Paper 10/174, International Monetary Fund, Washington. 
Louzis, D. P., Vouldis, A. T., \& Metaxas, V. L. (2012). Macroeconomic and bank-specific determinants of nonperforming loans in Greece: A comparative study of mortgage, business and consumer loan portfolios. Journal of Banking \& Finance, 36(4), 1012-1027.

Makri, V., Tsagkanos, A., \&Bellas, A. (2014). Determinants of non-performing loans: The case of Eurozone. Panoeconomicus, 61(2), 193-206.

Rasool, S., Dars, J. A., \& Shah, B. (2013). The Role of Commercial Banks in Production of Small and Medium Enterprises (SMEs) in Pakistan. Available at SSRN 2495796.

Rehman, R. U., Zhang, J., \& Ahmad, M. I. (2016). Political system of a country and its non-performing loans: a case of emerging markets. International Journal of Business Performance Management, 17(3), 241-265.

Richard, E. (2011). Factors that cause non-performing loans in commercial banks in Tanzania and strategies to resolve them. Journal of management policy and practice, 12(7), 50.

Saba, I., Kouser, R., \& Azeem, M. (2012). Determinants of Non-Performing Loans: Case of US Banking Sector. The Romanian Economic Journal, Year XV, 44.

Zhu, N., Wang, B., \& Wu, Y. (2014). Productivity, efficiency, and non-performing loans in the Chinese banking industry. The Social Science Journal

Shimizu, K. (2011). Bankruptcies of Small firms \& lending releationship. Journal of Banking \& Finance,36(3), 857870.

Swedberg, R. (2010). The structure of confidence and the collapse of Lehman Brothers. Research in the Sociology of Organizations, 30(A), 71-114.

World Bank, 2013. World development indicators. Retrieved from http://databank.worldbank.org/data/download/WDI-2013-ebook.pdf [Accessed March 28, 2016].

Young, R. D., Glennon, D., \& Nigro, P. (2007). Borrower-Lender Distance, Credit Scoring \& loan Performance: Evidence from International-Opaque Small Business Borrower. Journal of financial Intermediation, 17(1), $113-143$ 


\section{APPENDIX}

\section{Survey Questionnaire \\ Determinants Of Non Performing Loans Of Sme Sector}

Bank and branch name:

1. Since how long is the branch functioning?

- $<2$ Years

- 2-3 Years

- 3-5 Years

- 5 Years\& above

2. What is the minimum age (of SME) required for the granting of loan in your bank?

- $0-1$ years

- $2-3$ years

- 3-5 years

- More than 5 years

3. What is the NPL/total lending ratio of your branch for SMEs?

4. How does the bank determine the repayment capacity of the borrower firm?

- Sales

- Repayment Record

- Financial Statement Analysis

- Any other

5. Which is the preferred nature of collateral desired by bank?

- Residential

- Commercial

- Agricultural land

- Any other

6. Loans are sanctioned up-to which below mentioned degree of collateral

- $60 \%$

- $70 \%$

- $75 \%$

7. How does the bank ensure that true assessment of collateral is carried out?

- Via independent surveyor

- IBP approved valuator

- Consult market value of asset

- Any other

8. In your point of view, what is the main cause of NPLs?

- Improper selection of Borrowers.

- Improper appraisal of assets.

- Lack of supervision and follow up

- Natural calamities

- Willful default of the Borrowers 
9. What is the most effective measure adopted by the bank for handling NPLs?

- Constant dialogue With the Borrowers/negations

- Re-structuring/re-scheduling of debt

- Waiver of interest amount \& recovery of capital

- Sale of credit to third party

- Tribunal/judicial proceedings

10. In your point of view, what are the main debt problems being faced by SMEs in Pakistan?

(Please rank 1 to $5 ; 5$ being the most important and 1 being the least important):

\begin{tabular}{c|l|l}
\hline Sr no. & \multicolumn{1}{c}{ Problems } & \multicolumn{1}{c}{ Rank } \\
\hline 1 & High interest rates $(i)$ & \\
\hline 2 & Inflation & \\
\hline 3 & Lack of infrastructure & \\
\hline 4 & High electricity prices & \\
\hline 5 & Lack of Govt. Support/subsidies & \\
\hline
\end{tabular}

11. Up-to what extent you think economic conditions are responsible for default?

- Completely

- To a certain limit

- Not at all 


\section{NOTES}

